\title{
Simplifying informed consent for biorepositories: Stakeholder perspectives
}

\author{
Laura M. Beskow, MPH, PhD ${ }^{1,2}$, Joëlle Y. Friedman, $M S^{3}$, N. Chantelle Hardy, BA ${ }^{3}$, Li Lin, MS ${ }^{3}$, \\ and Kevin P. Weinfurt, $P h D^{2,3}$
}

\begin{abstract}
Purpose: Complex and sometimes controversial information must be conveyed during the consent process for participation in biorepositories, and studies suggest that consent documents in general are growing in length and complexity. As a first step toward creating a simplified biorepository consent form, we gathered data from multiple stakeholders about what information was most important for prospective participants to know when making a decision about taking part in a biorepository. Methods: We recruited 52 research participants, 12 researchers, and 20 institutional review board representatives from Durham and Kannapolis, NC. These subjects were asked to read a model biorepository consent form and highlight sentences they deemed most important. Results: On average, institutional review board representatives identified $72.3 \%$ of the sentences as important; researchers selected $53.0 \%$, and participants $40.4 \%(P=0.0004)$. Participants most often selected sentences about the kinds of individual research results that might be offered, privacy risks, and large-scale data sharing. Researchers highlighted sentences about the biorepository's purpose, privacy protections, costs, and participant access to individual results. Institutional review board representatives highlighted sentences about collection of basic personal information, medical record access, and duration of storage. Conclusion: The differing mandates of these three groups can translate into widely divergent opinions about what information is important and appropriate to include a consent form. These differences could frustrate efforts to move simplified forms - for biobanking as well as for other kinds of research-into actual use, despite continued calls for such forms. Genet Med 2010:12(9):567-572.
\end{abstract}

Key Words: informed consent, consent forms, biological specimen banks

B iorepositories are a key resource for the large-scale genomic research needed to advance personalized medicine. However, the collection and storage of biospecimens and data for future research use raises pressing issues concerning informed consent. Although biobanking and related procedures are usually considered to involve minimal risk, ${ }^{1}$ the process of obtaining consent for such activities often requires that participants

From the ${ }^{1}$ Center for Genome Ethics, Law \& Policy, Duke Institute for Genome Sciences \& Policy, Duke University; ${ }^{2}$ Duke Translational Medicine Institute, Duke University; and ${ }^{3}$ Center for Clinical \& Genetic Economics, Duke Clinical Research Institute, Duke University School of Medicine, Durham, North Carolina.

Dr. Laura M. Beskow, Duke Institute for Genome Sciences \& Policy, 240 North Building, Box 90141, Durham, NC 27708. E-mail: laura.beskow@duke.edu.

Disclosure: The authors declare no conflict of interest.

Supplemental digital content is available for this article. Direct URL citations appear in the printed text and are provided in the HTML and PDF versions of this article on the journal's Web site (www.geneticsinmedicine.org).

Submitted for publication April 1, 2010

Accepted for publication June 1, 2010.

Published online ahead of print August 11, 2010.

DOI: 10.1097/GIM.0b013e3181ead64d assimilate information that can be complicated or controversial. These challenges are intensified by the perception, substantiated in multiple studies, ${ }^{2-9}$ that consent documents in general are becoming both longer and harder to understand. As one observer noted, "[Consent forms] are growing in length and complexity, becoming ever more intimidating, and perhaps inhibiting rather than enhancing participants' understanding. Participants may not even read them, much less understand them." 10

Awareness of these problems has led to calls for the simplification of consent documents, ${ }^{11,12}$ including those used for biorepositories. The National Cancer Institute's Office of Biorepositories and Biospecimen Research has recommended that "... a 1-page informed consent document outlining important issues and risks in straightforward language should be developed and implemented." 13 One obstacle to developing such a form, however, is determining what is material information that a reasonable person would want to know to make an informed decision, as opposed to unnecessary detail that may confuse prospective participants and detract from information of more substantive importance. ${ }^{14}$ Studies have documented that what patients and research subjects deem essential may differ from information identified as important by "experts."15-17

As a first step toward creating a simplified biorepository consent form, we gathered data from multiple stakeholders, including research participants, researchers, and institutional review board (IRB) representatives, about what information was most important for prospective participants to know when making a decision about taking part in a biorepository. Here, we present their characterizations of the importance of individual items of information supplied in a model consent form, and discuss the implications of the differences observed among groups for creating usable simplified consent forms, for biobanking as well as for other kinds of research.

\section{METHODS}

The foundation for our study was a model biorepository consent form ${ }^{18}$ that was developed based on relevant U.S. federal regulations ${ }^{19,20}$ and guidance, ${ }^{21}$ best practice guidelines, ${ }^{1,22-24}$ and ethics literature about biobanking. Because this form had been specifically created to be succinct, we reincorporated all the details we thought prospective biorepository participants might plausibly wish to know (e.g., definitions of "genes" and "DNA"; details concerning how applications to study stored materials would be reviewed; options that would be available to those who wish to discontinue participation). According to readability tools available in Microsoft Word 2007 (Redmond, WA), the level of education required to understand this longer form (Appendix, Supplemental Digital Content 1, http://links.lww.com/GIM/A113) was U.S. grade 7.9 .

\section{Subject identification and recruitment}

We recruited subjects in Durham, NC (the home of the Duke University School of Medicine) and in Kannapolis, NC (the site 
of the Measurement to Understand Re-Classification of Disease of Cabarrus and Kannapolis [MURDOCK] Study, a populationbased registry focused on reclassifying diseases by applying advanced genomic and bioinformatics capabilities ${ }^{25}$ ). At the time our study commenced, the MURDOCK Study was in the planning stages for the creation of a repository of biospecimens and clinical data from 50,000 local residents. We enrolled subjects in three categories:

- Prospective biorepository participants: As part of a larger study, we mailed invitation letters to a stratified random sample of diabetes patients aged $\geq 18$ years who were drawn from community-based physician practices at each location. We chose diabetes patients to assemble a group who shared a common, complex health condition that could increase both their interest in research and their concern about health information privacy. The letter was printed on the treating physician's letterhead over his or her signature. Patients interested in participating contacted the study team and were screened over the telephone. Respondents were asked about their basic ability to speak and read English and were purposively selected to achieve diversity by sex, race, age, and level of education. Approximately half $(n=52)$ of the subjects enrolled were asked to read the longer consent form described here; the remainder were assigned to a group that read a shorter form (unpublished data).

- Researchers: We e-mailed invitation letters to all investigators $(n=12)$ associated with the MURDOCK Study, which included faculty from Duke and community-based physician researchers in Kannapolis. All 12 (100\%) completed the study activity.

- IRB representatives: We e-mailed invitation letters to Duke University Health System IRB chairs $(n=10)$ and to the members and chair of the Carolinas Medical CenterNortheast Medical Center IRB in Kannapolis $(n=15)$. Both locations have IRB oversight responsibilities for the MURDOCK Study. Of the 25 IRB representatives invited, $20(80 \%)$ took part.

\section{Design and procedures}

Study subjects were asked to read the biorepository consent form, first on paper and then for a second time on a tablet computer. Subjects were asked to use the tablet computer's electronic stylus to mark specific sentences they thought would be most important for persons who were considering taking part in a biorepository. Specifically, we instructed prospective biorepository participants:

As you go through the form this time, we would like you to highlight the sentences that - in your opinion-contain the most important information about taking part in a biorepository. In other words, highlight the sentences that have information that would matter most to you, if you were thinking about taking part in a biorepository.

Researchers and IRB representatives were instructed similarly to highlight the sentences they thought were most important for prospective participants to know to make a decision about taking part in a biorepository.

The consent documents tested in Durham and Kannapolis were identical, with the exception that those used with prospective biorepository participants in Durham referred to a "Duke Biorepository"; all others referred to a "MURDOCK Biorepository."
Study visits were conducted from October of 2008 through March of 2009. During these visits, study staff instructed subjects in operating the tablet computer and demonstrated how to highlight sentences using the stylus. Staff were available throughout the visit (which lasted $\sim 45 \mathrm{~min}$ ) to answer questions and address any difficulties with the technology. Prospective biorepository participants were compensated with a \$25 gift card; researchers and IRB representatives were not compensated.

The Duke University Health System and Carolinas Medical Center-Northeast Medical Center IRBs approved the component of this study involving prospective biorepository participants and these subjects provided informed consent. Both IRBs deemed the components of this study involving researchers and IRB representatives to be exempt, and these subjects were informed that responding to the invitation letter by participating in the research activity would be taken as consent.

\section{Data analysis}

Participants' data were downloaded directly from the tablet computer application for analysis in SAS version 9.1 (SAS Corporation, Cary, NC). Differences in demographic characteristics were examined using exact Pearson $\chi^{2}$ tests. We compared the number of sentences that each group highlighted using the Tukey-Kramer multiple-comparison test ("honestly significant difference test" for unequal sample sizes). For each group, we then created a separate rank-ordered list of all the sentences in the consent form based on the proportion that endorsed each item. We assigned topic areas to each sentence based on the section of the consent form in which it was located to compare the general subject matter of the sentences each group most often selected as important. Finally, we compiled a list containing the 10 sentences most frequently selected by each group, and assessed differences in the proportion of each group that endorsed each one using exact Pearson $\chi^{2}$ tests. A $P$ value of $<0.05$ was considered significant for all assessments.

\section{RESULTS}

\section{Subject characteristics}

Study subjects were similar across the three groups in terms of sex, race, and ethnicity (Table 1). There were, however, significant differences by age: significantly more prospective biorepository participants were $>55$ years of age when compared with researchers $(P<0.01)$ and IRB representatives $(P<0.01)$.

\section{Number of sentences highlighted}

Of the 207 sentences in the form, IRB representatives on average identified $149.7(72.3 \%)$ as important; researchers selected 109.8 (53.0\%); and participants selected 83.7 (40.4\%). The difference in the mean number of sentences IRB representatives highlighted when compared with participants was significant (TukeyKramer multiple comparison adjusted $P=0.0002)$. The difference between IRB representatives and researchers (Tukey-Kramer multiple comparison adjusted $P=0.17)$ and between researchers and participants (Tukey-Kramer multiple comparison adjusted $P=$ 0.37 ) was not statistically significant.

Sentence-by-sentence results (Fig. 1) demonstrate the overall tendency of IRB representatives to select more sentences as important. Thus, for any given sentence, there was a high likelihood that a greater proportion of IRB representatives would have selected it relative to the other groups. This finding points to the importance of examining two other outcomes: (1) the topics of the sentences each group most often identified as important; and (2) whether the proportions of each group 


\begin{tabular}{|c|c|c|c|}
\hline & $\begin{array}{l}\text { Participants } \\
(N=52)\end{array}$ & $\begin{array}{c}\text { Researchers } \\
(N=12)\end{array}$ & $\begin{array}{c}\text { IRB } \\
(N=20)\end{array}$ \\
\hline$n$ & $\%$ & $\%$ & $\%$ \\
\hline
\end{tabular}

\begin{tabular}{|c|c|c|c|c|c|c|}
\hline \multicolumn{7}{|l|}{ Age, years } \\
\hline$<55$ & 13 & $(25.0)$ & 9 & $(75.0)$ & 13 & $(65.0)$ \\
\hline$\geq 55$ & 39 & $(75.0)$ & 3 & $(25.0)$ & 7 & $(35.0)$ \\
\hline \multicolumn{7}{|l|}{ Sex } \\
\hline Female & 30 & $(57.7)$ & 6 & $(50.0)$ & 9 & $(45.0)$ \\
\hline Male & 22 & $(42.3)$ & 6 & $(50.0)$ & 11 & $(55.0)$ \\
\hline \multicolumn{7}{|l|}{ Ethnicity (Hispanic) } \\
\hline No & 52 & $(100.0)$ & 11 & $(91.7)$ & 20 & $(100.0)$ \\
\hline Yes & 0 & $(0.0)$ & 1 & (8.3) & 0 & $(0.0)$ \\
\hline \multicolumn{7}{|l|}{ Race } \\
\hline White & 43 & $(82.7)$ & 9 & $(75.0)$ & 20 & $(100.0)$ \\
\hline Other than white & 9 & $(17.3)$ & 3 & $(25.0)$ & 0 & $(0.0)$ \\
\hline \multicolumn{7}{|l|}{ Level of education ${ }^{a}$} \\
\hline $\begin{array}{l}\text { Less than bachelor's } \\
\text { degree }\end{array}$ & 26 & $(50.0)$ & - & - & - & - \\
\hline $\begin{array}{l}\text { Bachelor's degree or } \\
\text { higher }\end{array}$ & 26 & $(50.0)$ & - & - & - & - \\
\hline
\end{tabular}

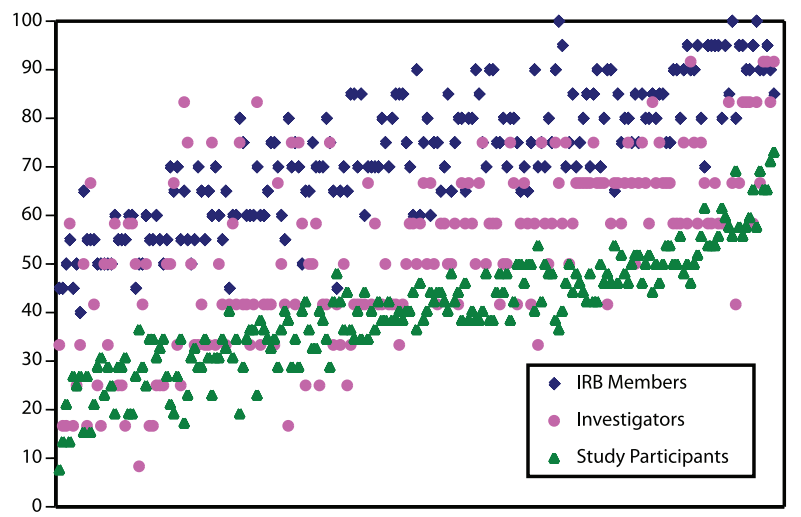

Fig. 1. Consent form sentences selected as important, by group (ordered by mean of group proportions).

that identified these top-ranked sentences as important differed significantly.

\section{Rankings: Topics of sentences most often highlighted}

The sentences most often selected as important by participants conveyed information about the kinds of individual research results that might be offered if they took part in the biorepository, as well as privacy risks and the fact that identifying information would not be released as part of large-scale data sharing (Table 2). In comparison, researchers most often highlighted sentences related to the purpose of the biorepository, privacy protections, costs, and participant access to indi- vidual results, whereas IRB representatives highlighted sentences about collection of basic personal information, medical record access, and duration of storage. The only sentence that ranked among the top 10 for all three groups dealt with privacy protections: "We will not give researchers your name or any other information that could identify you without your permission."

\section{Proportions: Agreement and disagreement in the sentences most often highlighted}

Several sentences were top-ranked among only one or two of the three groups; however, the proportions of each group that selected those sentences as important did not differ significantly (Table 2). These included sentences about large-scale data sharing, privacy risks, the privacy protection afforded by not placing research data in medical records, and the narrow circumstances in which individual research results would be offered to biorepository participants.

For many of the sentences that were top-ranked in at least one group, however, there were significant differences in the proportions of each group that selected it (Table 2). Sentences that IRB representatives selected significantly more often than did participants and researchers concerned the collection of demographic information and family health history, the unlimited length of time that specimens and data would be stored, a summary of which aspects of biorepository participation were optional, and the options that would be available to participants who wanted to discontinue participation.

Sentences that both IRB representatives and researchers selected significantly more often than did participants were related to the purpose of the biorepository, the collection of basic personal information, re-contact about additional research, and the fact that participants would not be offered individual results as a matter of routine.

\section{DISCUSSION}

A primary purpose of informed consent is to allow competent individuals to decide for themselves whether or not to participate in research. This process involves three elements: (1) disclosing information to potential participants; (2) ascertaining that they understand the information; and (3) ensuring that their agreement to take part is voluntary. ${ }^{26}$ Current regulatory and procedural frameworks, however, tend to emphasize disclosure requirements, which can lead to complicated consent documents that contain an overwhelming level of detail. ${ }^{27}$ Failure to attend to the importance of comprehension and voluntariness may undermine the basic ethical principle of respect for persons and the goals of informed consent.

In actuality, as Wendler and Grady ${ }^{28}$ point out, investigators do not need to disclose, nor do potential participants need to understand, all there is to know about research. Not only is there too much to know but also much of this information is not needed to give valid informed consent. Rather, the extent and nature of the information disclosed should focus on what a reasonable person needs to make an autonomous decision. ${ }^{27,29}$

In this study, we gathered data from multiple stakeholders to begin addressing calls to simplify and refocus consent forms - in this case, a biorepository consent form. Starting with a model form that was developed based on federal regulations and best practice guidelines, we sought input to ensure that a further simplified form would contain the information most important for prospective participants to know about taking part in a biobank. Between the different stakeholder groups, we 
Table 2 Sentences most often selected as important, by group

\begin{tabular}{|c|c|c|c|c|}
\hline Topic & Sentence & Participants & Researchers & IRB \\
\hline Purpose & $\begin{array}{l}\text { We are asking you to let us store some of your blood so it might be used in } \\
\text { these kinds of studies. }{ }^{a, c}\end{array}$ & $46.2 \%$ & $91.7 \%$ & $90.0 \%$ \\
\hline Voluntary & Taking part in research is completely voluntary. ${ }^{a, b}$ & $59.6 \%$ & $58.3 \%$ & $95.0 \%$ \\
\hline Right to refuse & $\begin{array}{l}\text { No matter what you decide, now or in the future, it will not affect your } \\
\text { medical care. }{ }^{a, b, d}\end{array}$ & $65.4 \%$ & $58.3 \%$ & $95.0 \%$ \\
\hline $\begin{array}{c}\text { Biospecimen } \\
\text { collection }\end{array}$ & $\begin{array}{l}\text { If you agree, we will draw } 50 \mathrm{ml} \text { (about } 3 \text { tablespoons) of blood from a } \\
\text { vein in your arm by needle stick. }{ }^{a}\end{array}$ & $55.8 \%$ & $83.3 \%$ & $95.0 \%$ \\
\hline \multirow{4}{*}{$\begin{array}{l}\text { Collection of } \\
\text { Basic } \\
\text { information }\end{array}$} & We will get some information about you and your health. ${ }^{a, c}$ & $17.3 \%$ & $83.3 \%$ & $65.0 \%$ \\
\hline & This will include things like name, age, sex, and racial or ethnic group. ${ }^{a, b}$ & $36.5 \%$ & $66.7 \%$ & $100.0 \%$ \\
\hline & We will also ask about your family's health history. ${ }^{a, b}$ & $40.4 \%$ & $58.3 \%$ & $95.0 \%$ \\
\hline & $\begin{array}{l}\text { If you agree, we will contact you no more than once a year to update this } \\
\text { information. }^{a}\end{array}$ & $57.7 \%$ & $83.3 \%$ & $85.0 \%$ \\
\hline $\begin{array}{l}\text { Medical Record } \\
\text { Access }\end{array}$ & We will get some information from your medical record. ${ }^{a}$ & $57.7 \%$ & $83.3 \%$ & $100.0 \%$ \\
\hline $\begin{array}{l}\text { Duration of } \\
\text { Storage }\end{array}$ & $\begin{array}{l}\text { There is no limit on the length of time we will keep your blood and } \\
\text { information. }{ }^{a, b}\end{array}$ & $55.8 \%$ & $66.7 \%$ & $100.0 \%$ \\
\hline $\begin{array}{l}\text { Research } \\
\text { recontact }\end{array}$ & $\begin{array}{l}\text { We may contact you in the future with offers to take part in other } \\
\text { research., }\end{array}$ & $23.1 \%$ & $83.3 \%$ & $70.0 \%$ \\
\hline \multirow[t]{2}{*}{$\begin{array}{l}\text { Large-Scale } \\
\text { Data Sharing }\end{array}$} & $\begin{array}{l}\text { Your name and other information that could identify you will never be } \\
\text { released into a scientific database. }\end{array}$ & $69.2 \%$ & $66.7 \%$ & $90.0 \%$ \\
\hline & Nobody will know just from looking at a database that the information & $69.2 \%$ & $41.7 \%$ & $80.0 \%$ \\
\hline
\end{tabular}
belongs to you.

\begin{tabular}{|c|c|c|c|}
\hline Privacy Risks & $\begin{array}{l}\text { There is a risk that someone could get access to the data we have stored } \\
\text { about you. }\end{array}$ & $71.2 \%$ & $83.3 \%$ \\
\hline \multirow[t]{3}{*}{$\begin{array}{l}\text { Privacy } \\
\quad \text { Protections }\end{array}$} & $\begin{array}{l}\text { We will not give researchers your name or any other information that could } \\
\text { identify you without your permission. }{ }^{a}\end{array}$ & $65.4 \%$ & $91.7 \%$ \\
\hline & $\begin{array}{l}\text { We will not give information that identifies you to anyone without your } \\
\text { permission, except if required by law. }{ }^{a}\end{array}$ & $57.7 \%$ & $83.3 \%$ \\
\hline & $\begin{array}{l}\text { We will not place any information that we get or create as part of this } \\
\text { project in your medical record. }\end{array}$ & $61.5 \%$ & $66.7 \%$ \\
\hline
\end{tabular}

\begin{tabular}{|c|c|c|c|c|}
\hline Costs & $\begin{array}{l}\text { There are no costs to you or your insurance for taking part in the } \\
\text { Biorepository. }{ }^{a}\end{array}$ & $65.4 \%$ & $91.7 \%$ & $90.0 \%$ \\
\hline Payments & You will not be paid for taking part in the Biorepository. ${ }^{a}$ & $59.6 \%$ & $83.3 \%$ & $90.0 \%$ \\
\hline \multirow{2}{*}{$\begin{array}{l}\text { Individual } \\
\text { Research } \\
\text { Results }\end{array}$} & $\begin{array}{l}\text { You should not expect to get individual results from research done using } \\
\text { your sample. }{ }^{b, c}\end{array}$ & $44.2 \%$ & $83.3 \%$ & $85.0 \%$ \\
\hline & $\begin{array}{l}\text { We will offer to tell you a finding like this only if it is about a disease that } \\
\text { is likely to cause early death if not treated. }\end{array}$ & $73.1 \%$ & $91.7 \%$ & $85.0 \%$ \\
\hline \multirow[t]{6}{*}{ Options } & You can choose to take part or not in the following: & & & \\
\hline & $\begin{array}{l}\text { - Letting us contact you no more than once a year to update your personal } \\
\text { information. }{ }^{a, b}\end{array}$ & $53.8 \%$ & $66.7 \%$ & $95.0 \%$ \\
\hline & $\begin{array}{l}\text { - Letting us use your medical record from time to time to update your } \\
\text { health information. }\end{array}$ & $55.8 \%$ & $58.3 \%$ & $95.0 \%$ \\
\hline & $\begin{array}{l}\text { - Letting us contact you no more than twice a year with offers to take part } \\
\text { in more research. } .^{a, b}\end{array}$ & $51.9 \%$ & $58.3 \%$ & $95.0 \%$ \\
\hline & $\begin{array}{l}\text { - Letting some of your genetic and health information be released, with no } \\
\text { direct identifiers, into both publicly accessible and restricted scientific } \\
\text { databases. }{ }^{a, b}\end{array}$ & $50.0 \%$ & $58.3 \%$ & $95.0 \%$ \\
\hline & No matter what you decide, now or in the future, it will not affect your & $61.5 \%$ & $58.3 \%$ & $80.0 \%$ \\
\hline
\end{tabular}




\begin{tabular}{|c|c|c|c|c|}
\hline Topic & Sentence & Participants & Researchers & IRB \\
\hline \multirow[t]{4}{*}{$\begin{array}{l}\text { Right to } \\
\text { Withdraw }\end{array}$} & $\begin{array}{l}\text { If you agree to take part in the Biorepository, you are free to change your } \\
\text { mind at any time. }{ }^{a, b}\end{array}$ & $57.7 \%$ & $66.7 \%$ & $95.0 \%$ \\
\hline & $\begin{array}{l}\text { At that time, we will send you a form so that you can tell us in writing } \\
\text { what you want us to do. For example: }\end{array}$ & & & \\
\hline & $\begin{array}{l}\text {-Unlink: This means we would forever remove the link between the code } \\
\text { number and your name. }{ }^{a, b}\end{array}$ & $53.8 \%$ & $58.3 \%$ & $95.0 \%$ \\
\hline & $\begin{array}{l}\text { - No further use: This means we would No longer give researchers your } \\
\text { sample or information. } .^{a, b}\end{array}$ & $53.8 \%$ & $58.3 \%$ & $95.0 \%$ \\
\hline
\end{tabular}

Bolded values denote sentences that were among the 10 most often selected by that group; columns that contain $>10$ cells with bold text are due to ties.

${ }^{a}$ Statistically significant differences between IRB v. participants.

${ }^{b}$ Statistically significant differences between IRB v. researchers.

cStatistically significant differences between researchers v. participants.

${ }^{d}$ This sentence appeared twice in the form.

found significant differences in both the number of sentences identified as containing important information, as well as in the topics of the sentences that were identified as being important. One explanation may be the diverse motivations that exist across the three groups.

A likely motivation among research participants is to understand efficiently the choice being presented to them. In other words, they want to spend as much time as necessary, but no more, obtaining information and making a decision about taking part in research. This might explain why in our study, they selected fewer sentences on average when compared with the other groups. Participants are of course ideally situated to provide input on what they would like to know to make a knowledgeable and voluntary decision. The National Bioethics Advisory Commission recommended in multiple reports that prospective participants can provide valuable insights into the type of information other potential subjects might want to learn by involving them in the design of studies and the informed consent process. , $27,30,31^{2}$

Researchers' goals include maximizing enrollment of eligible participants within the constraints of ethically acceptable approaches to recruitment and consent. At the same time, they are likely motivated by a desire to minimize delays in the IRB review process and may see adherence to IRB template language with the fewest possible study-specific additions or deletions as the path of least resistance. Informally, one researcher in our study commented that she found it challenging to remain true to the instruction to highlight sentences containing information she considered most important for prospective participants to know because, as she went through the form, she instead found herself thinking, "The IRB expects to see this, the IRB wants to see that." Therefore, although research teams have first-hand experience with obstacles to the informed consent process, such as those raised by lengthy, complex forms, they may perceive little incentive to bring these matters to the attention of the IRB.

IRB representatives in particular confront several potentially conflicting mandates:

- Protect research participants: The purpose of IRB review is to ensure that appropriate steps are taken to protect the rights and welfare of research participants. To approve a study, the IRB must determine that risks to subjects are necessary, minimized, and reasonable in relation to anticipated benefits; that selection of subjects is equitable; that informed consent is obtained and documented appropri- ately (when required); and that adequate provisions are made to ensure subjects' safety and to protect privacy and confidentiality (Title 45, Part 46 of the Code of Federal Regulations; subsection. 111a).

- Ensure regulatory compliance: Although IRBs are broadly charged with ethical review, they are ultimately held responsible primarily for procedure and documentation. ${ }^{27}$ Avoiding adverse enforcement action by a federal oversight agency can be a compelling source of motivation for IRBs, ${ }^{32}$ leading to excessively cautious interpretations and undermining efforts to streamline IRB practices - and all without enhancing participant protections. ${ }^{33}$

- Guard against institutional liability: As noted by the Institute of Medicine, consent forms have been ". . . hijacked as 'disclosure documents' for the risk management purposes of research organizations," with the interests of the institution overwhelming the interests of the participant. ${ }^{34}$ A common refrain we heard in general conversation with IRB representatives was, "We like the idea of a simpler form, but the lawyers require us to have all this language."

A strength of our study was that our consent form was written below an eighth grade reading level, making it accessible to research participants as well as to the other stakeholders. Our sample size was relatively small, which limited our power to detect, for example, differences between IRB representatives and researchers in the number of sentences identified as important. However, we believe our data effectively demonstrate the widely divergent opinions of these three groups - potentially because of differing mandates - regarding the importance of various items of information in a consent form. These differences could frustrate efforts to move simplified forms into actual use, despite continued calls for such forms and ongoing projects aimed at developing them. ${ }^{35}$ This applies not just to biobanking consent forms, but to those used for other kinds of research that involve more risk and where the need for simpler forms that participants actually read and understand is arguably even greater.

Thus, reconciling these differences is a critical area for future endeavor. This resolution should be in the direction of ensuring that the focus of the informed consent process and form is on informing and protecting research participants. A simplified biobanking form should include the basic elements required by federal regulations for the protection of human research subjects, as well as additional topics recommended as best practice for biobanking (e.g., participant access to research results, development of commercial products). This information should be 
conveyed in clear, straight-forward language, with the level and types of detail guided by data such as those presented here concerning what participants most want to know. Research is needed to identify innovative ways of providing additional details for those participants who desire them, such as supplemental brochures and "Frequently Asked Questions." Finally, tools are needed that can be used during the consent process to ensure voluntariness and assess comprehension of the most important information.

\section{ACKNOWLEDGMENTS}

This study was supported by funding from the Measurement to Understand Re-Classification of Disease of Cabarrus and Kannapolis (MURDOCK) Study and by a Grant from the National Institutes of Health Clinical and Translational Science Award 1UL1RR024128 to Duke University.

The authors thank Jonathan McCall of the Duke Clinical Research Institute for editorial assistance and manuscript preparation. The authors also thank Ashley Dunham, Laveina Dash, Whitney McLeod, and Maria Fawzy for their assistance implementing this study. We worked with hesketh.com (Raleigh, NC) to develop the tablet PC application.

\section{REFERENCES}

1. National Bioethics Advisory Commission. Research involving human biological materials: ethical issues and policy guidance, Vol. 1. Rockville, MD: National Bioethics Advisory Commission, 1999

2. LoVerde ME, Prochazka AV, Byyny RL. Research consent forms: continued unreadability and increasing length. $J$ Gen Intern Med 1989;4:410-412.

3. Grossman SA, Piantadosi S, Covahey C. Are informed consent forms that describe clinical oncology research protocols readable by most patients and their families? J Clin Oncol 1994;12:2211-2215.

4. White LJ, Jones JS, Felton CW, Pool LC. Informed consent for medical research: common discrepancies and readability. Acad Emerg Med 1996;3: $745-750$.

5. Silverman H, Hull SC, Sugarman J. Variability among institutional review boards' decisions within the context of a multicenter trial. Crit Care Med 2001;29:235-241.

6. Paasche-Orlow MK, Taylor HA, Brancati FL. Readability standards for informed-consent forms as compared with actual readability. $N$ Engl J Med 2003;348:721-726

7. Sharp SM. Consent documents for oncology trials: does anybody read these things? Am J Clin Oncol 2004;27:570-575.

8. Beardsley E, Jefford M, Mileshkin L. Longer consent forms for clinical trials compromise patient understanding: so why are they lengthening? J Clin Oncol 2007;25:e13-e14.

9. Albala I, Doyle M, Appelbaum PS. The evolution of consent forms for research: a quarter century of changes. IRB 2010;32:7-11.

10. Case study. Is longer always better? Hastings Cent Rep 2008;38:10.

11. National Cancer Institute. Simplification of informed consent documents, 1998. Available at: http://www.cancer.gov/clinicaltrials/understanding/ simplification-of-informed-consent-docs. Accessed April 1, 2010.

12. Association of American Medical Colleges. AAMC Reporter. Informed consent documents group: keep it simple, 2007. Available at: http://www. aamc.org/newsroom/reporter/oct07/informedconsent.htm. Accessed April 1, 2010 .

13. National Cancer Institute. Office of Biorepositories and Biospecimen Research. Custodianship and ownership issues in biospecimen research, 2007.
Available at: http://biospecimens.cancer.gov/global/pdfs/CaOSumm.pdf. Accessed April 1, 2010.

14. Shickle D. The consent problem within DNA biobanks. Stud Hist Philos Biol Biomed Sci 2006;37:503-519.

15. Rudd RE, Comings JP. Learner developed materials: an empowering product. Health Educ Q 1994;21:313-327.

16. Reid JC, Klachko DM, Kardash CA, Robinson RD, Scholes R, Howard D. Why people don't learn from diabetes literature: influence of text and reader characteristics. Patient Educ Couns 1995;25:31-38.

17. Turner S, Maher EJ, Young T, Young J, Vaughan Hudson G. What are the information priorities for cancer patients involved in treatment decisions? An experienced surrogate study in Hodgkin's disease. Br J Cancer 1996; 73:222-227.

18. Beskow LM, Dean E. Informed consent for biorepositories: assessing prospective participants' understanding and opinions. Cancer Epidemiol Biomarkers Prev 2008;17:1440-1451.

19. Code of Federal Regulations. Title 45, Part 46. Protection of human subjects, 2005. Available at: http://www.hhs.gov/ohrp/humansubjects/guidance/45cfr46. htm. Accessed April 1, 2010.

20. Code of Federal Regulations. Title 45, Parts 160 and 164. Standards for privacy of individually identifiable health information, final rule, 2006. Available at: http://www.hhs.gov/ocr/privacy/hipaa/administrative/privacy rule/privruletxt.txt. Accessed April 1, 2010.

21. U.S. Department of Health and Human Services. Office for Human Research Protections. Guidance on research involving coded private information or biological specimens, 2008. Available at: http://www.hhs.gov/ohrp/human subjects/guidance/cdebiol.htm. Accessed April 1, 2010.

22. National Cancer Institute. Best practices for biospecimen resources, 2007 Available at: http://biospecimens.cancer.gov/global/pdfs/NCI_Best_Practices_ 060507.pdf. Accessed April 1, 2010.

23. Eiseman E, Bloom G, Brower J, et al. Case studies of existing human tissue repositories. "Best Practices" for a biospecimen resource for the Genomic and Proteomic Era. Santa Monica, CA: RAND Corporation, 2003.

24. International Society for Biological and Environmental Repositories. 2008 best practices for repositories: collection, storage, retrieval, and distribution of biological materials for research. Cell Preserv Technol 2008;6:5-58.

25. The MURDOCK Study. Measurement to understand the reclassification of disease of Cabarrus/Kannapolis. Available at: https://www.murdock-study. com/. Accessed April 1, 2009.

26. Faden RR, Beauchamp TL. History and theory of informed consent. New York, NY: Oxford University Press, 1986

27. National Bioethics Advisory Commission. Ethical and policy issues in research involving human participants, Vol. 1. Rockville, MD; US Government Printing Office, 2001

28. Wendler D, Grady C. What should research participants understand to understand they are participants in research? Bioethics 2008;22:203-208.

29. National Commission for the Protection of Human Subjects of Biomedical and Behavioral Research. The Belmont Report: ethical principles and guidelines for the protection of human subjects of research. Washington DC: US Government Printing Office, 1979.

30. National Bioethics Advisory Commission. Research involving persons with mental disorders that may affect decisionmaking capacity, Vol. 1. Rockville, MD: US Government Printing Office, 1998.

31. National Bioethics Advisory Commission. Ethical and policy issues in international research: clinical trials in developing countries, Vol. 1. Rockville, MD: US Government Printing Office, 2001.

32. Koski G. Beyond compliance. . . is it too much to ask? IRB 2003;25:5-6.

33. Emanuel EJ, Wood A, Fleischman A, et al. Oversight of human participants research: identifying problems to evaluate reform proposals. Ann Intern Med 2004;141:282-291.

34. Institute of Medicine. Responsible research: a systems approach to protecting research participants. Washington, DC: National Academies Press, 2002.

35. Koyfman SA, McCabe MS, Emanuel EJ, Grady C. A consent form template for phase I oncology trials. IRB 2009;31:1-8. 